\title{
Future Configurable Transport for the Ageing Population
}

\author{
Anna S. F. Chang $^{1} \quad$ Roy S. Kalawsky ${ }^{2}$ \\ 1.2. Wolfson School of Mechanical, Electrical \& Manufacturing Engineering \\ Loughborough University, Leicestershire, U.K. \\ 'E-mail: a.s.f.chang@lboro.ac.uk ²E-mail: r.s.kalawsky@lboro.ac.uk
}

\begin{abstract}
Loneliness and inactivity can adversely affect physical health. Encouraging older people to be active can have health benefits and reduce isolation. New approaches are needed to ensure that growing numbers of older people are able to remain active and mobile during later life. The new design of the configurable e-mobility can support older people in maintaining their independence and quality of life.
\end{abstract}

Keyword-Future transport for elderly, mobility for ageing society, configurable EV

\section{INTRODUCTION}

The increase in the number of older people in the population will require new solutions to transport problems. Older people tend to adopt technologies later, (or not at all), so new transport designs must ensure that older people are able to get from point A to $\mathrm{B}$ without difficult to use technology. Loneliness has a negative impact on the wellbeing of human beings regardless of age. For this reason, encouraging older people to travel and stay active will decrease and delay healthcare needs and costs.

\section{Aging Population Profile}

In the 2012 Ageing Report by the European Commission [1], shows changes in aging population groups and subgroups.

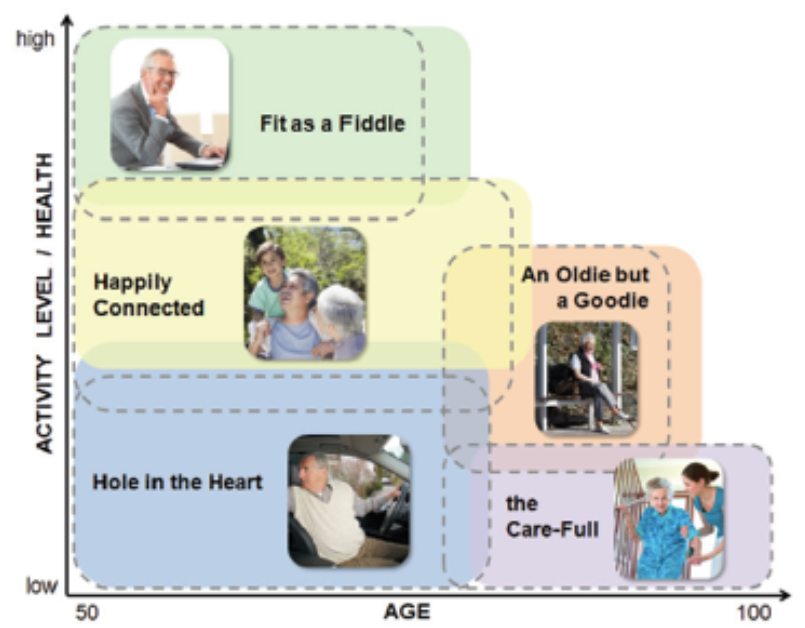

Fig 1: Profiles of Older people in 2050 pursuant to age and activity level (dashed the current position of the profile)

Source: Goal Transport Needs for Aging Society Action Plan

Across the board, all the profiles are increasing from year 2010 to 2030 and 2050. Retirement age will be changing: instead of retiring between the ages of 58-64, older people will be retiring between 61-67 years old. Fig 1 shows the Profile of Older People. The Oldie but a Goodie and The Care-Full experience the biggest change with increases of $66 \%$ and $78 \%$ respectively in 2050 on 2010 data in the report.

The profile descriptions are extracted from the report [1] as follows:
Fit as a Fiddle. The majority of this group will still be employed. Private transport will still be the dominant mode of transport until this group is unable to drive and must use public transport.

Hole in the Heart $(\mathrm{HH})$. This group profile experiences physical limitations not mental limitations. Technology can positively impact this group because it allows these older people to remain in the workforce thus increasing quality of life.

Happily Connected (HC). This group enjoys an active social life with close family and friend connections. These older people mainly use private cars as means of transport and fly by plane for international travel.

An Oldie but a Goodie (OG). This age group is between 8090 years old. Technology will have huge impact on their mobility. Typically many in this group will not travel to new places, but with the support of adequate travel information and assistance, barriers to mobility will be removed. Increased mobility will lead to improved health and improved independence.

The Care Full (CF). This group of older people have physical/mental health limitations. Healthcare support is required. New communication technologies will help this group communicate with relatives.

For the purpose of this mobility design competition, the Oldie but a Goodie (OG) and Hole in the Heart $(\mathrm{HH})$ will be our target profiles.

\section{ACTIVE TRAVE}

\section{A. Transport Policy in the U.K.}

The UK Government is investing significant resources into improving transport. These include improving rail connections in the North of England, at around $£ 50$ bn on HS2 [2] and starting construction on the Crossrail 2 rail project[3] at around $£ 30$ b. These projects are undoubtedly important to improve the country's economy and create employment, but many older people who don't work will not enjoy the benefit of these investments.

\section{B. Mobility for Wellbeing}

From the project report by ILC-UK and Age UK [4], using data from UK English Longitudinal Study of Ageing (ELSA)[5], a study was conducted to find out whether the transport needs of older people are being met, and how this has changed over time. It was shocking to see that $32 \%$ of those 65 and over never use public transport, whilst another $27 \%$ use it once a month or less. The declining age to use public transport regularly starts around at just after 75 . The report findings further critised that the UK transport system is failing to meet 
the needs of many older people. Fig 2 show the frequency of older people using public transport between 2012-2013.

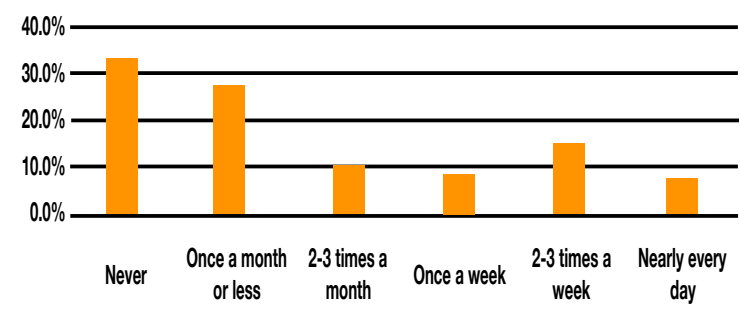

Fig 2: How often do older people use public transport? Source: English Longitudinal Study of Ageing wave 6, 2012-13

\section{Promoting Active Travel}

Studies show that leg muscle strength of an 80 -year-old can be $40 \%$ weaker than those aged 30 [6]. As age increases, the risk of falls also increases and travel becomes less appealing; what's more, slower walking pace syndrome starts to appear. This is caused by loss of sensory cells by up to $40 \%$ by the age of 70 [7]. The vestibular system is essential for the body's balance, the loss of sensory cells affects our stability and strength, leading to imbalance. Recognising how older bodies change can allow us to invent transport suitable for the elderly. Aided walking apparatus seems to be an important consideration. A U.K. study conducted between 2012-13 [1] revealed that many over $65 \mathrm{~s}$ are not using public transport is because it is not convenient; some older people are not using public transport because it does not go where they want and other older people say their health prevents them from using public transport. Table 1 shows the type of trips desired by older people. It was surprised to read that going to the GP has higher importance than meet-up with friends elsewhere. Clearly, health concern is more important over leisure. If the mobility design to allows the older person to travel with ease - anytime and anywhere they want (within reason) - then it will improve their quality of life, or at the least, make transport to their GPs more convenient.

\begin{tabular}{|l|l|}
\hline Food shopping & $17 \%$ \\
\hline Shopping for other goods & $9 \%$ \\
\hline Visit family & $8 \%$ \\
\hline Visit friends at home & $6 \%$ \\
\hline Go to GP & $6 \%$ \\
\hline Meet-up with friends elsewhere & $5 \%$ \\
\hline Out of town shopping & $5 \%$ \\
\hline Go to place of interest & $5 \%$ \\
\hline Go to hospital & $4 \%$ \\
\hline Post office & $3 \%$ \\
\hline $\begin{array}{l}\text { Bank/Building society } \\
\text { Table 1: Types of trips desired by old people } \\
\text { Source: Department for Transport (2001) }\end{array}$ \\
\hline
\end{tabular}

Those of us who has an older person in the family will know that elderly people need to go to the toilet more frequently and need to sit down and rest when traveling long distances. For this reason, not having enough public benches and toilets will prevent older people from going and staying outside. Sadly, data from The British Toilet Association (2013) revealed that the number of public toilets across the UK fell $40 \%$ between year 2003 and 2013 [8]. The future assistive mobility devices should be designed to promote walking, support balance and be able to transform to eMobility when necessary.

\section{Transport to Health Services}

It is concerning to read [4] that many older people start to find it difficult to attend their GP appointments because of a transportation problem on average at 77 years old. A similar pattern is observed for individuals who find it hard to travel to hospital. Older people need regular appointments to visit their GPs because their health needs must be monitored [9]. Skipping appointments is not advised. A novel independent eMobility is called for to help the ageing population.

\section{PROMOTING INDEPENDENT TRAVEL - CONFIGURABLE EV CONCEPT}

Statistics from the Department of Transport [10] reveal that $12 \%$ of those aged $60-69$, and $31 \%$ of those aged 70 and over, have a mobility difficulty of some kind. A mobility difficulty may mean difficulty going out on foot, a problem using public transportation or even difficulties getting in and out of a car.

The new design of the configurable eMobility may be the answer to prolong their mobility independence. A gyroscope walking stick can provide tremendous support to an elderly person - because the walking cane can stand up on its own, users can use their balance to stay upright. With GPS, hands free mobile phone function and health monitoring on the walking stick handle bar allows vital communication technologies to sync.

\section{A. Configurable parts}

Customizable vehicles are not new. These vehicles have occupied the popular imagination for years in cartoons. Fig 3 shows the transformer that is a classic configurable vehicle. The parts can be connected in different manners to create different shapes and functions. The moving parts in transformer are based on robotic control. The engine of the vehicle must be configured to provide motion control of each unit. The wheels are designed to power up separately. This is the most difficult part of such a design. The improved version should use an electric system.

The limbs, joints and moving surfaces are reconfigured using the concept of the moving surface in primary fight control system that is Yaw and Pitch control and the secondary fight control system such as slat, flap and spoiler.

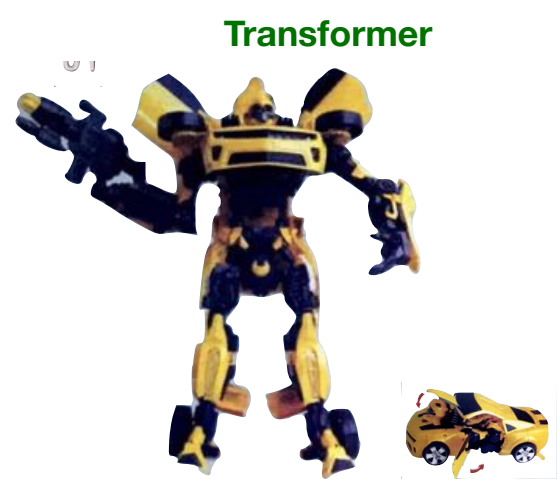

Fig 3: Inspiration from the Transformer 
Robotic control, the most difficult part, is the central of gravity stability. This is still one of the most difficult research part for configurable vehicle or robot. Fig 4 shows the concept of gyroscope that is a starting point of the robot, but the balancing for each individual part is configured structure is needed to be actively calculated or preprogrammed.

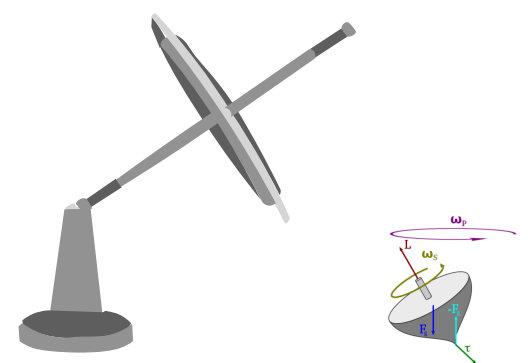

Fig 4: Gyroscope built-in to maintain stability

\section{B. Present configurable mobility system}

The most commonly acceptable configurable vehicle is the wheelchair. Fig 5 shows a wheelchair that has two functions. One is the typical wheelchair for linear transportation on the road. Another is its vertical extension motion. The vehicle motion allows the seat to stand up through the motion control to the wheelchair surfaces of back, seat, leg holder and the foot rest. The wheelchair can then allow the users to stand through the robotic control to change from surface to surface angle $90^{\circ}$ to $180^{\circ}$ to upright the wheelchair.

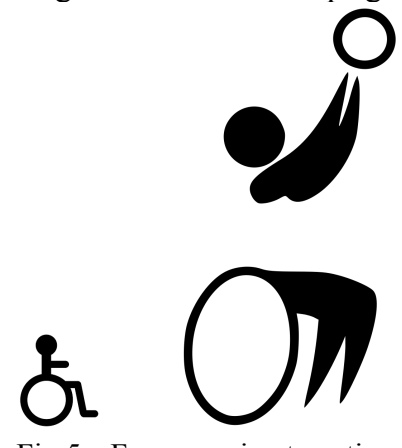

Fig 5: From passive to active

\section{EV CONCEPT TO WHEELCHAIR}

A number of the existing technology in EV can well be applied to configurable vehicle. A foldable wheelchair is the desire. Fig 6 shows the idea to build a foldable wheel chair - a highly portable wheelchair is the target. The final target size is not a foldable suitcase, but to a walking stick that can stand upright on its own.

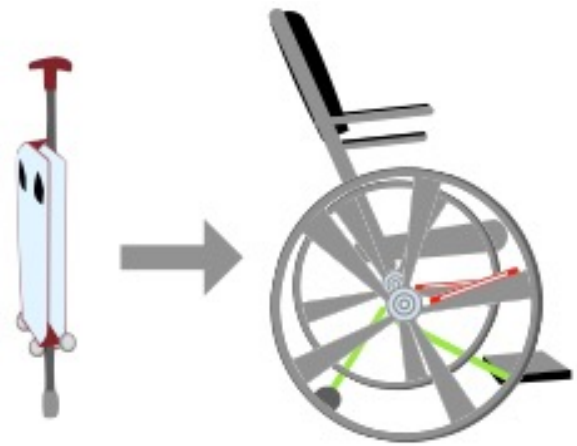

Fig 6: From walking stick to eMobility

\section{A. What advanced components is needed}

Firstly, the wheel is designed with electric joint as shown in Fig 7. The joints form parts of the rim and the spokes design should be reduced to a few in order to implement the spoke joints. The tires are configured with partition so that it is also foldable.

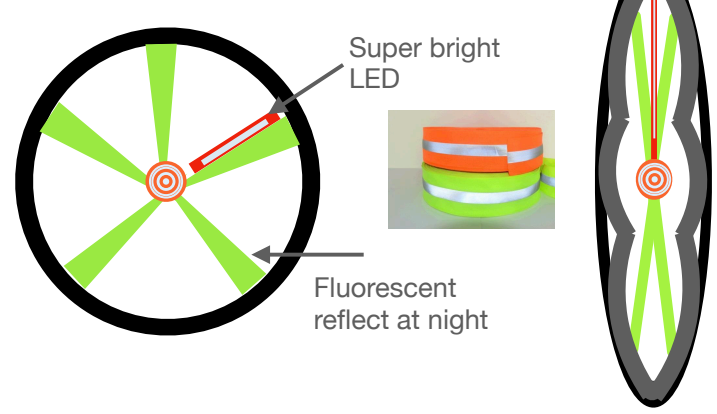

Fig 7: From round wheel to thin wheel

\section{B. Sensors and monitoring}

In order to make the proposed unit have additional functions, smart sensors should be installed in the handle bar. It consists of pressure, temperature and humid sensors in order to make decisions on the users' health and operational condition. Necessary action is then made, such as communication with the call center for assistance. Fig 8 shows the concept. The final product will look like a special walking stick as shown in Fig 9 and 10. The designer will also pay attention to the outlook of the walking stick. Besides attractive patterns available, the walking apparatus will also include fluorescent retroreflective strips to aid visibility and a small super bright LED light.
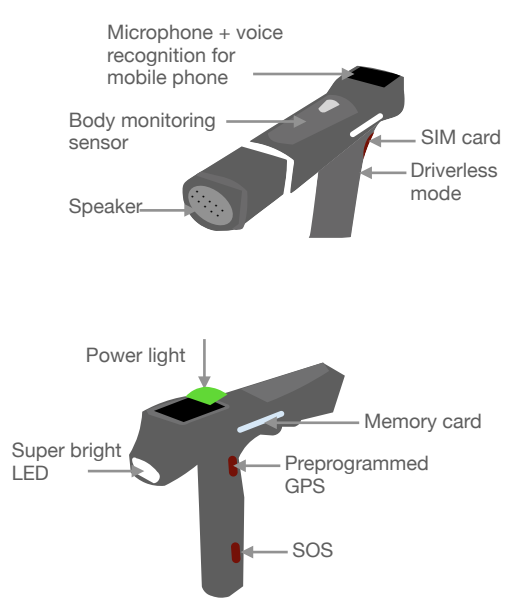

Fig 8: Handle bar built in functions

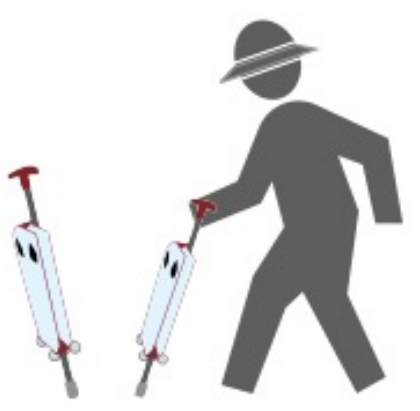

Fig 9: Gyroscope walking stick for aided balance. Stay upright on its own. Transform to vehicle when needed. 


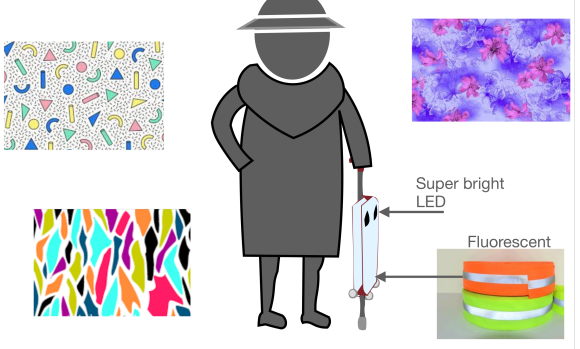

Fig 10: Turing the walking stick into a fashion item

\section{IN WHEEL MOTOR DESIGN AND OTHER MOTOR CONTROL}

\section{A. In-wheel motor}

The most important part of the configurable EV is the in-wheel motor. It is the integration of the motor and the wheel [11]. Only electrical signal and power line is needed to control the wheel. No mechanical connection from engine to the wheel is needed. Of course for electric wheel chair, the motion is purely from electric motor. Fig 11 shows the example of inwheel motor.

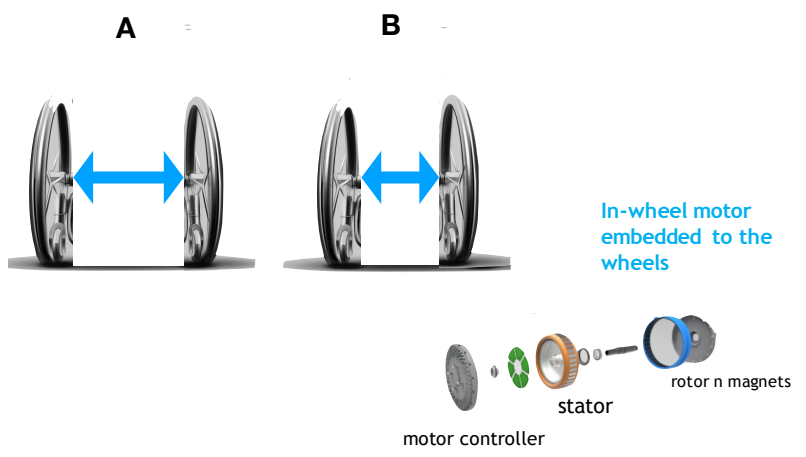

Fig 11: In-wheel motor and dimension control

\section{B. Linear motor}

In order to realize the vertical extension of wheel chair, a number of linear and rotational motor will be adopted. The linear motor is an unfolded rotational motor and allows linear motion between the stator and the translator. All the parts and surface can be moved using such linear motor design. They are all electric driven and they also have fault tolerance because it is based on switched-reluctance motor concept that is of high degrees of safety.

The final design of the configurable electric wheelchair is shown in Fig 12 and Fig 13. It has the function of:

- Foldable

- In-wheel motor

- Vertical extension

- High packaging factor

- $\quad$ Light weight

The frame is made of aluminum ore magnesium that has a $40 \%$ and $30 \%$ respective weight as compared with steel or iron. Today using a special forming technique, the strain and stress factor of the magnesium can be reinforced to the same as steel.

The concept is not only limited to wheelchair, it can also be used for inflatable boat as shown in Fig 14. The ultimate goal is the wheelchair and foldable boat can inter-configurable.

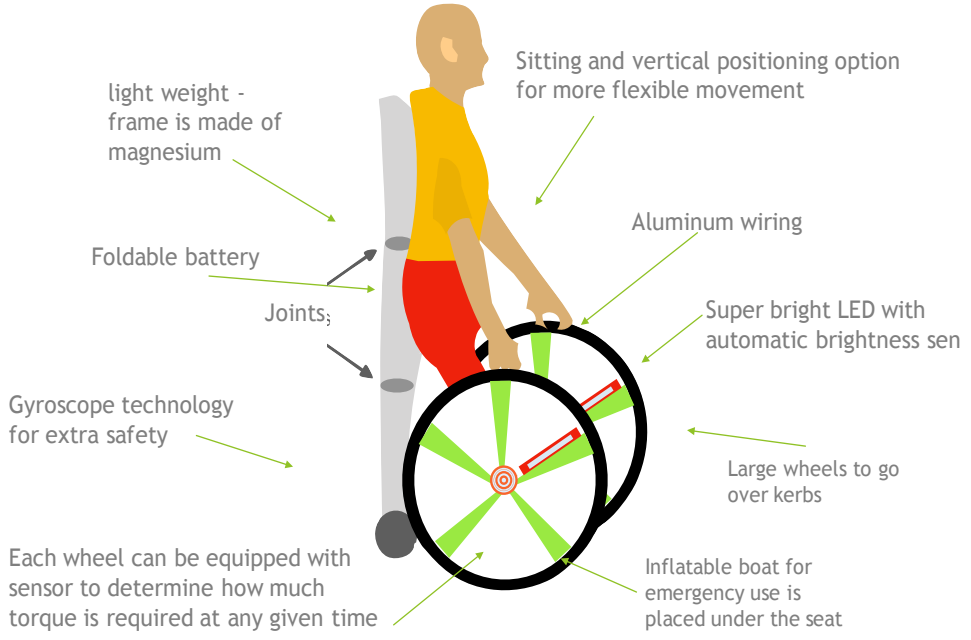

Fig 12: Feature of the new eMobilty

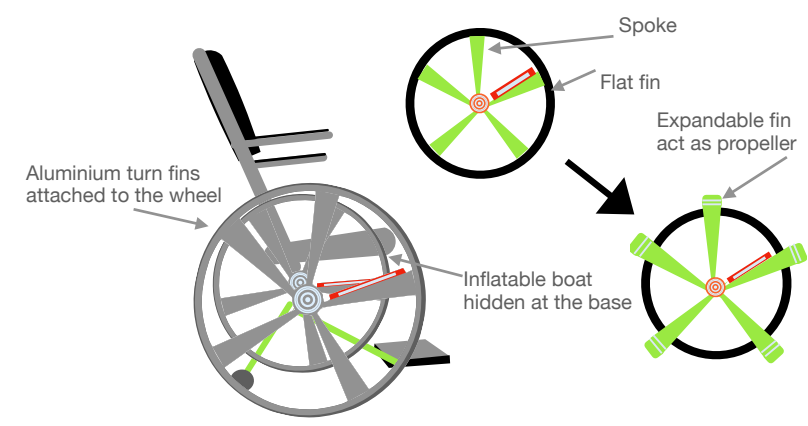

Fig 13: Aluminum fins act as propeller

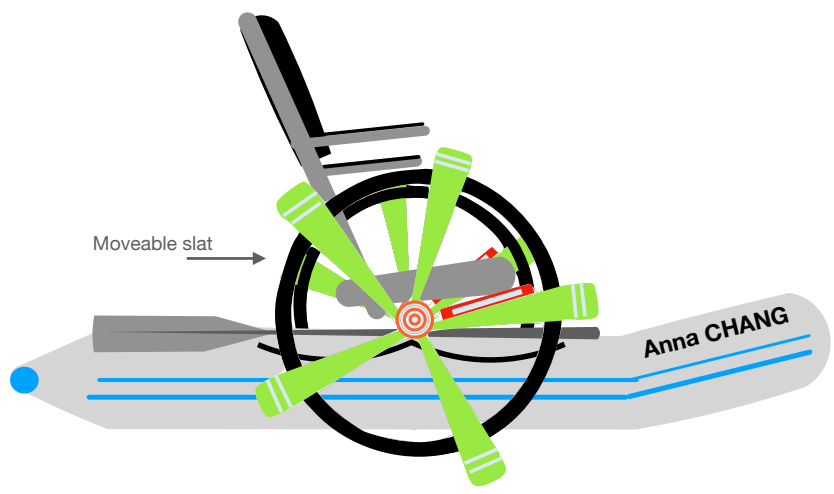

Fig 14: Inflatable boat in case of emergency

\section{CONCLUSION}

If the new eMobilty meet the needs of older people, it will boost their social activity rate, thus, leading to better health and reduce isolation. The driverless feature and GPS could enable older people to extend their travel range and provide safer driving for a longer age. The hands free mobile device and instant body condition monitoring feature are important features for them to stay in touch.

Evidence suggests that people who travel more regularly are more active has better health. New approaches are needed to ensure that growing numbers of older people are able to remain active and mobile during later life.

A new concept of using electric motion devices can realize such concept. Together with the intelligent motion control and light-weight materials, such e-mobility with configurable function is to target design for all mobility designers and users. 


\section{REFERENCES}

[1] J. Johnson, H. Evers, S. M. Peace, O. U. A. S. C. Team., and O. U. D. of H. and S. Welfare., "An ageing society," 1994.

[2] L. Handley, "What is HS2 and how much will it cost?," The Guardian, 28-Apr-2017.

[3] A. Plimmer, G., Bounds, “London’s £30bn Crossrail 2 project moves a step forward,” Financial Times, p. 2017, Jul-.

[4] Holley-Moore and H. Creighton, "The Future of Transport in an Ageing Society," Age UK, no. June, 2016.

[5] "English Longitudinal Study of Ageing." [Online]. Available: https://www.elsa-project.ac.uk/. [Accessed: 16-Nov-2017].

[6] G. Aniansson, A., Hedberg, M., Henning, G. \& Grimby, "Muscle morphology, enzymatic activity and muscle strength in elderly men: a follow up study," Muscle and Nerve, vol. 9, pp. 585-591, 1986.
[7] W. Rosenhall, U., \& Rubin, "Degenerative changes in the human vestibular sensory epithelia," Acta Otolaryngolia, vol. 79, pp. 67-81, 1975 .

[8] "Why do we need more and better toilets?," The British Toilet Association (2013). [Online]. Available: http://www.btaloos.co.uk/. [Accessed: 12-Nov-2017].

[9] B. Beach, "Serious illness in the over 50s," no. February, 2015.

[10] R. Mackett, "Overcoming the barriers to access for older people University College London," no. November, 2014.

[11] X. D. Xue, K. W. E. Cheng, T. W. Ng, and N. C. Cheung, " Multi-Objective Optimization Design of In-Wheel Switched Reluctance Motors in Electric Vehicles", IEEE Trans Industrial Electronics, Vol. 57 , Issue: 9, 2010 , pp. 2980 - 2987.

[12] Zhu Zhang; Cheung, N.C.; Cheng, K.W.E.; Xue, X.D.; Lin, J.K.; "Longitudinal and Transversal End-Effects Analysis of Linear Switched Reluctance Motor", IEEE Transactions on Magnetics, Vol. 47 , Issue: 10, 2011 , pp. $3979-3982$. 